Research Article

$\mathrm{J}$ Exp Clin Med

2021; 38(2): 159-166

doi: 10.52142 omujecm.38.2.19

\title{
Does maxillary expansion improve hearing loss due to otitis media with effusion?
}

\author{
Özlem SANCAKTAR ${ }^{1}$, Abdullah Alper ÖZ ${ }^{2}$ (i), Mehmet Eser SANCAKTAR ${ }^{3, *(\mathbb{D}}$ \\ ${ }^{1}$ Department of Orthodontics, Dental Care Hospital, Samsun, Turkey \\ ${ }^{2}$ Department of Orthodontics, Faculty of Dentistry, Ondokuz Mayıs University, Samsun, Turkey \\ ${ }^{3}$ Department of Otolaryngology, Samsun Training and Research Hospital, Samsun, Turkey
}

\begin{abstract}
\begin{tabular}{ccccc}
\hline Received: 15.07 .2020 & $\bullet$ & Accepted/Published Online: 10.01 .2021 & $\bullet$ & Final Version: 14.03 .2021 \\
\hline
\end{tabular}
Abstract

Some authors emphasized that maxillary expansion had a positive effect on impaired hearing due to otitis media with effusion (OME). The goal of this study was to compare the improvement of hearing loss degrees of patients treated with rapid maxillary expansion (RME) and patients watched for spontaneous resolution. This study was conducted with audiometric and tympanometric records of 22 patients with OME. Group 1 consisted of patients who had OME and needed RME ( $\mathrm{n}=12)$, and group 2 consisted of patients who had OME and were observed for spontaneous resolution ( $\mathrm{n}=10$ ). In-group 1, records were taken before expansion (T0), just after RME (T1), after the retention period (T2), and 6 months after expansion (T3). In-group 2, T0 and T2 records were taken. In-group 1, hearing levels improved and air-bone gaps (ABG) decreased significantly after RME $(\mathrm{p}<0.05)$. This improvement showed a relapse with $\mathrm{T} 2$ and $\mathrm{T} 3$ records. In-group 2, no significant change was observed in hearing levels but ABG levels decreased significantly $(\mathrm{p}<0.05)$. The extent of healing level was not significantly different between the maxillary expansion and control groups when T2-T0 records were compared. The results of this study indicated that RME improved hearing levels and decreased ABG after expansion in children with OME; however, a relapse occurred after the retention. ABG levels in both groups exhibited similar decreases after retention. RME, although it is not a major treatment for OME, it can be said that it has positive effects for OME when applied within orthodontic indication.
\end{abstract}

Keywords: Hearing loss, maxillary expansion, otitis media with effusion

\section{Introduction}

Otitis media with effusion (OME) is defined as the presence of fluid without signs or symptoms of acute infection in the middle ear (Rosenfeld et al., 2016). The presence of thick mucus or fluid in the middle ear may lead to conductive hearing loss and this condition (OME) is the most common cause of hearing problems in early childhood (Rosenfeld et al., 2016; Kılıç et al., 2016). Genetic predisposition, bacterial biofilm infection, and poor Eustachian Tube (ET) function could be among the common etiologic factors (Gan et al., 2016). 90\% of children have on average, four episodes of OME every year before school age (Rosenfeld et al., 2016). OME is uncommon among children older than 12 years and the natural history is likely to differ from younger children. The target population includes children with or without developmental disabilities or underlying conditions that predispose to OME (Rosenfeld et al., 2004). Therefore, clinicians should determine whether other conditions coexist that put a child at risk, and then take these conditions into consideration during management. Although children with craniofacial anomalies known to have a higher prevalence of chronic OME, studies of the relationship between OME and hearing loss typically exclude children with craniofacial anomalies and other developmental disorders (Rosenfeld et al., 2004).

It has been reported that maxillary contraction and palatal anatomy have a correlation with conductive hearing loss (Villano et al., 2006; Peyvandi et al., 2014). If the transversal dimension of the maxilla is narrow and high maxillary palatal arches are present, the levator and tensor veli palatini muscles which open and close the pharyngeal orifice of the ET may be in a hypofunctional position (Ross, 1971). Hypofunction of these muscles may cause obstruction of the mucus deflection 
and prevent air passage in the middle ear (Villano et al., 2006).

Although maxillary expansion is often used initially to correct transversal problems such as posterior cross bite, there are other possible indications including, mobilization of the maxillary sutural system, broadening the smile, and reduction in nasal resistance (McNamara and Brudon, 1993). Expansion increases the transverse dimension of the maxilla by opening the midpalatal suture, and corrects the palatal anatomy and the ends of the muscles positioned near the ET. Stretching of the tensor and veli palatini muscles after maxillary expansion promotes ventilation of the middle ear by opening the nasopharyngeal orifice of the ET (Zhang et al., 2010). There are also data in the orthodontic literature suggesting that correcting palatal anatomy by maxillary expansion improves hearing levels of patients with conductive hearing loss due to OME (Timms, 1997; Ceylan et al., 1996; Taşpınar et al., 2003; Kılıç et al., 2008).

The initial management of OME includes watchful waiting for spontaneous resolution for at least three months from the date of effusion onset (if known) or three months from the date of diagnosis (if onset is unknown) without any treatment (Rosenfeld et al., 2004; Rosenfeld et al., 2016; Venekamp et al., 2016). After watchful waiting, 50\% of OME patients' problems resolve spontaneously (Gan et al., 2016). At least $25 \%$ of OME episodes persist for $\geq 3$ months and may be associated with hearing loss, poor school performance, behavioral problems (Rosenfeld et al., 2016). Another common treatment option of OME is insertion of a ventilation tube via a surgical procedure in the condition of having persistence of effusion for three months or longer (chronic OME) (Rosenfeld et al., 2013; Kuo et al., 2014; Kılıç et al., 2016).

Maxillary expansion is not primarily a treatment for OME, but is one of the favorable outcomes when correcting the jaw. Thus, OME is not the indication for maxillary expansion.

In the literature, most of the studies were conducted without any control group, and so there is no adequate comparison of the role of maxillary expansion in OME. Thus, the aims of this clinical study were to assess the hearing levels of patients treated with rapid maxillary expansion and to compare the improvement in hearing levels of expansion patients with patients that were watched for spontaneous resolution.

\section{Materials and methods}

This prospective study was conducted after the approval of the local ethics committee of the institute. The patients between $\geq 10$ and $\leq 15$ years which diagnosed as OME by same otolaryngologist were consulted to same orthodontist for further examination if the children have an orthodontic problem such as posterior crossbite, high palatal arches. This age range was chosen because it is also an ideal age range for maxillary expansion, if indicated. Patients were divided into two groups as described below.

Group 1 were selected according to the following criteria:
(1) $\geq 10$ and $\leq 15$ age, (2) bilateral or unilateral conductive hearing loss due to OME (3) no ventilation tube placement before and no medical treatment in the previous three months, (4) posterior crossbite, (5) high palatal arches.

Group 2 were selected according to the following criteria: (1) $\geq 10$ and $\leq 15$ age, (2) bilateral or unilateral conductive hearing loss due to OME (3) no ventilation tube placement before and no medical treatment in the previous three months, (4) normal palatal anatomy, (5) no maxillary crossbite.

In both groups, the patients/caregivers gave their informed consent. Patients with allergies, systemic disorders, operation history, adenoid hypertrophy, and cleft lip-palate were excluded. The follow-up period for each patient in group 1 was six months, and in Group 2 was three months. All of the parents/caregivers were informed that children may experience reduced hearing until the effusion resolves, especially if bilateral. And some useful suggestions (speaking in close proximity, facing the child and speaking clearly, repeating phrases when misunderstood, and providing preferential classroom seating) for optimizing the listening and learning environment were made until the effusion resolves. Children in both group were reexamined every month by same otolaryngologist during the study period, in respect of worsening hearing, or structural abnormalities of the eardrum or middle ear if needed for further intervention.

In Group 1, acrylic bonded type expansion appliances were fabricated according to the patient's maxillary study models (Fig.1). Before bonding of the appliance all posterior teeth were cleaned and pumiced. Next $37 \%$ solution of phosphoric acid was applied to the cusp tips of the involved teeth. A lightcured adhesive (Transbond Plus, Light Cure Band Adhesive, 3M Unitek, Monrovia, CA, USA) was used to bond the appliances. The screw was activated two times a day until 3 mm overexpansion was achieved. The same appliance was used for retention after an active expansion period for three months. Fixed orthodontic brackets and a transpalatal arch were bonded after the expansion appliance was removed.
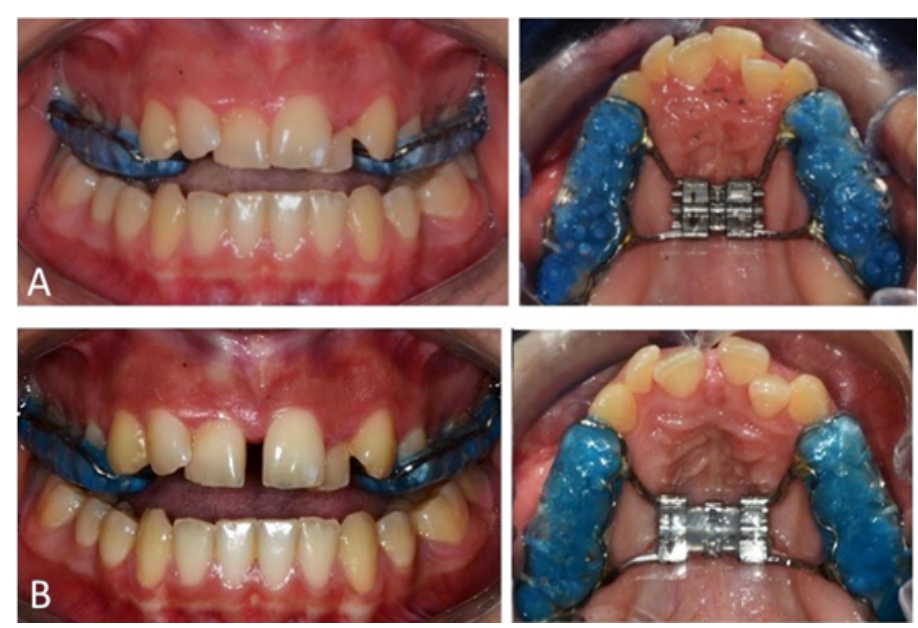

Fig. 1. A) Bonded type expansion appliance before maxillary expansion B) after maxillary expansion 
In Group 2, the patients were watched for three months for spontaneous healing. During this time, they did not receive medical treatment (such as nasal steroids, antibiotics, and antihistamines).

\subsection{Pure-tone audiometry and tympanometry}

Pure-tone audiogram was used to assess the hearing thresholds. Audiologic tests were performed with AC 40 clinical audiometer (Interacoustics A/S, Assens, Denmark). The puretone thresholds at $250 \mathrm{Hertz}(\mathrm{Hz}), 500 \mathrm{~Hz}, 1000 \mathrm{~Hz}$ and 2000 $\mathrm{Hz}$ and air-bone gaps at $500 \mathrm{~Hz}, 1000 \mathrm{~Hz}$ and $2000 \mathrm{~Hz}$ were recorded. The thresholds at speech frequencies of $4000 \mathrm{~Hz}$ and $8000 \mathrm{~Hz}$ were excluded from this study because high frequencies are affected by middle-ear mass or inner-ear nerve damage.

Air-bone gap is a method of diagnosing conductive hearing loss and it is the difference in audiometric hearing thresholds using bone and air conduction. We performed pure tone audiogram using a fail criterion of $>20 \mathrm{~dB} \mathrm{HL}$ at one or more frequencies in either ear, and calculated air-bone gaps for 500 $\mathrm{Hz}, 1000 \mathrm{~Hz}$ and $2000 \mathrm{~Hz}$ frequencies. The measurements were made for both ears at each frequency. All of the children were 10 years or older, so suitable for conventional audiometry, in which the child pushes on a bottom when a stimulus is heard.

Tympanometry was also used to evaluate the middle ear pressure, and tympanic compliance. GSI TympStar Version 2 Middle Ear Analyzer (Grason-Stadler, Inc., Milford, NH) device with $226 \mathrm{~Hz}$ probe tone and TDH-39 earphone (Telephonics, USA) was used. Tympanometry is an objective test measuring the amount of sound energy reflected back with a small probe placed in the ear canal. ET function, tympanic membrane mobility and middle ear function can be evaluated objectively and be recorded graphically.

Pure-tone audiometric and tympanometric records of each patient in Group 1 were taken before rapid maxillary expansion (T0), after satisfactory expansion was achieved (T1), after a three-month retention period (T2), and six months after expansion (T3). In Group 2 the audiometric records were taken at the beginning of the watching period (T0) and three months after watching for spontaneous resolution (T2). All of the puretone audiometric and tympanometric measurements were made by same audiologist.

The mean pure-tone thresholds and air-bone gaps were calculated for each subject and used for statistical analysis. None of the patients used any drugs or experienced any surgical procedure during the whole study period in both groups.

\subsection{Statistical analysis}

All statistical analyses were performed using a software package (SPSS version 23, Chicago, MI, USA). Descriptive statistics of tympanometric measurements and hearing levels, and air-bone gaps at different frequencies were calculated for $\mathrm{T} 0, \mathrm{~T} 1, \mathrm{~T} 2$, and $\mathrm{T} 3$ in group 1, for T0 and T2 in Group 2. All of the data from right and left ears averaged together. ShapiroWilk normality tests were conducted for quantitative data. For intra-group comparison, in Group 1 the audiometric records at different times were compared using repeated-measure analysis of variance (ANOVA) with Bonferroni correction or the Friedman test according to the distribution of the data. In Group 2 the paired sample t-test or Wilcoxon test was used.

The change in hearing level and air-bone gaps from the first record period to the three-month retention period or the three months after watching for spontaneous resolution period (T0T2) was calculated for each variable. The groups were then compared using the independent sample t test. The level of significance was set at $\mathrm{p}<0.05$

\section{Results}

Our subjects were totally 22 patients (11 boys, 11 girls) between 10 and 15 years old with a mean age of 12 years and four months. Group 1 consisted of 12 patients between 10 and 15 years old with a mean age of 12 years seven months old. Group 2 consisted of 10 patients between 10 and 15 years old with a mean age of 12 years one month old. The follow-up period for each patient in Group 1 was six months, and in Group 2 was three months.

Table 1 summarizes the pure-tone thresholds, and air-bone gaps of the Group 1 for each ear. The mean values and standard deviations at T0 and T2 time records for Group 2 are shown in Table 2. In Group 1, there was a significant difference between hearing levels and air-bone gaps recorded at different times (Table 3-4).

The hearing levels and air-bone gaps were decreased just after maxillary expansion but this healing exhibited a degree of relapse after the retention period. However, there was no significant difference between the pure-tone thresholds of T0 and T2 records of Group 2 (Table 3). Figs. 2 and 3 summarize the change in hearing levels and air-bone gaps of the groups.

The air-bone gaps showed a significant decrease in Group 2, which was watched for spontaneous resolution for three months (Table 4). There were also no significant differences between the pressure and tympanic compliance values in different times in both groups. However, volume records showed a significant difference in Group 1 after the retention period (Table 5). There was no significant difference between the healing amounts (T2-T0) of the groups. The mean hearing level difference was $2.71 \pm 6.29 \mathrm{~dB}$ in Group 1 and $1.44 \pm 8.12$ $\mathrm{dB}$ in Group 2.

The extent of hearing level decrease was not significantly different between the maxillary expansion and control groups. The mean air-bone gap decrease was $2.85 \pm 5.1 \mathrm{~dB}$ in Group 1 and $3.76 \pm 4.9 \mathrm{~dB}$ in Group 2. There was also no significant difference between the groups when the air-bone gap decreases were compared (Table 6). 


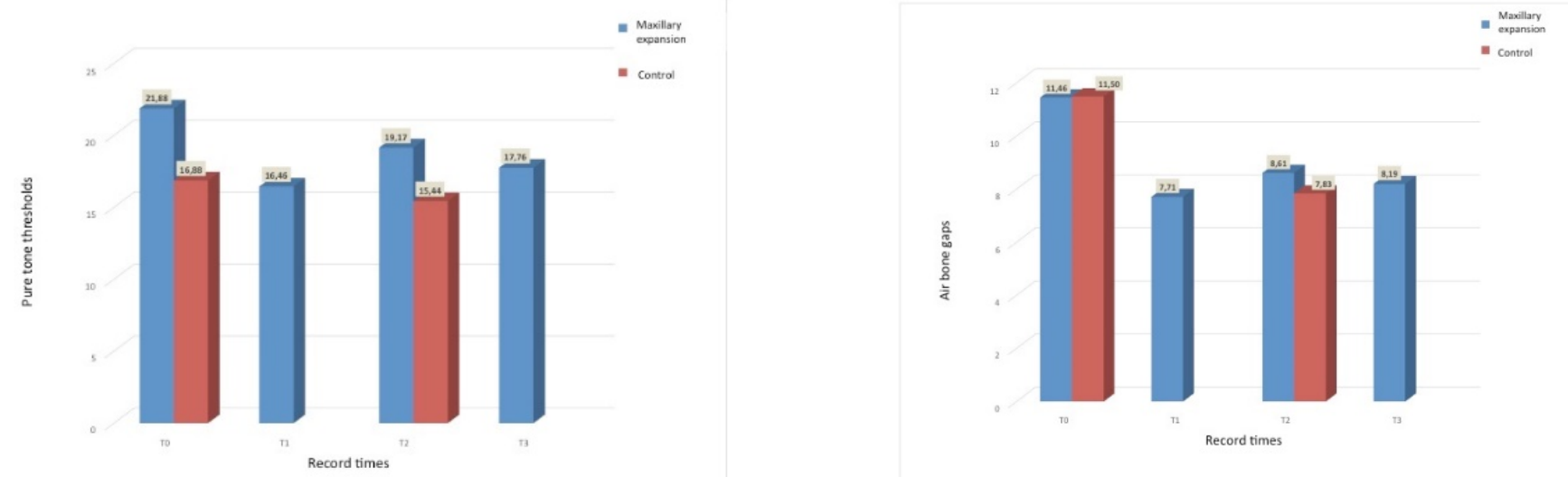

Fig. 2. Change of pure tone thresholds measurements of the groups during time
Fig. 3. Change of air bone gap measurements of the groups during time

Table 1. Means and standard deviations of pure-tone thresholds, air-bone gaps at various speech frequencies of group 1

\begin{tabular}{|c|c|c|c|c|c|c|c|c|}
\hline \multirow[b]{2}{*}{ Frequency (Hz) } & \multicolumn{2}{|c|}{ T0 } & \multicolumn{2}{|c|}{ T1 } & \multicolumn{2}{|c|}{$\mathbf{T 2}$} & \multicolumn{2}{|c|}{ T3 } \\
\hline & $\begin{array}{l}\text { Mean } \\
(\mathrm{dB})\end{array}$ & Std & $\begin{array}{l}\text { Mean } \\
(\mathrm{dB})\end{array}$ & Std & $\begin{array}{l}\text { Mean } \\
(\mathrm{dB})\end{array}$ & Std & $\begin{array}{l}\text { Mean } \\
(\mathrm{dB})\end{array}$ & Std \\
\hline \multicolumn{9}{|l|}{$\begin{array}{c}\text { PTT }^{\text {a }} \\
250 \mathrm{~Hz}\end{array}$} \\
\hline Right ear & 23.33 & 12.30 & 20.42 & 9.40 & 22.92 & 13.89 & 21.25 & 13.67 \\
\hline Left ear & 28.75 & 8.29 & 17.92 & 5.41 & 22.08 & 10.54 & 18.75 & 7.72 \\
\hline \multicolumn{9}{|l|}{$500 \mathrm{~Hz}$} \\
\hline Right ear & 19.17 & 11.44 & 17.08 & 8.64 & 20.00 & 13.48 & 17.50 & 12.70 \\
\hline Left ear & 28.33 & 12.85 & 18.33 & 9.61 & 21.25 & 16.25 & 19.58 & 12.69 \\
\hline \multicolumn{9}{|l|}{$1000 \mathrm{~Hz}$} \\
\hline Right ear & 18.33 & 13.20 & 13.75 & 10.68 & 17.92 & 13.39 & 15.42 & 12.51 \\
\hline Left ear & 23.75 & 14.00 & 16.67 & 12.30 & 18.75 & 19.32 & 17.92 & 14.99 \\
\hline \multicolumn{9}{|l|}{$2000 \mathrm{~Hz}$} \\
\hline Right ear & 14.58 & 9.40 & 12.50 & 8.39 & 15.00 & 10.00 & 15.42 & 10.96 \\
\hline Left ear & 18.75 & 16.39 & 15.00 & 15.37 & 15.42 & 16.57 & 16.25 & 15.39 \\
\hline \multicolumn{9}{|l|}{$\begin{array}{l}\text { ABG }^{b} \\
500 \mathrm{~Hz}\end{array}$} \\
\hline Right ear & 12.50 & 8.39 & 7.92 & 7.52 & 12.08 & 10.96 & 10.00 & 10.87 \\
\hline Left ear & 17.50 & 7.83 & 10.42 & 8.38 & 10.83 & 8.74 & 9.58 & 6.20 \\
\hline \multicolumn{9}{|l|}{$1000 \mathrm{~Hz}$} \\
\hline Right ear & 11.25 & 10.47 & 7.08 & 8.10 & 10.00 & 10.87 & 8.33 & 10.94 \\
\hline Left ear & 14.17 & 7.33 & 10.83 & 10.18 & 6.67 & 8.87 & 7.92 & 6.20 \\
\hline \multicolumn{9}{|l|}{$2000 \mathrm{~Hz}$} \\
\hline Right ear & 6.25 & 5.69 & 5.00 & 6.74 & 6.67 & 8.61 & 7.08 & 8.38 \\
\hline Left ear & 7.08 & 7.52 & 5.00 & 6.03 & 5.42 & 6.55 & 6.25 & 7.72 \\
\hline
\end{tabular}

${ }^{\mathrm{a}}$ : Pure-tone thresholds, ${ }^{\mathrm{b}}$ :Air-bone gap

\section{Discussion}

OME is defined as the presence of fluid in the middle ear without signs or symptoms of acute ear infection which may lead to conductive hearing loss. There have been several factors that can cause OME, including viral upper respiratory infection, acute otitis media, dysfunction of the ET, allergy, residual bacterial antigens, and biofilm (Berkman et al., 2013). Patients with cleft palate, Down syndrome, and other craniofacial anomalies also have a high risk because of compromised function of the Eustachian tube (Flynn et al., 2009) Conductive hearing loss is more likely in patients with mouth breathing because of reduction in the nasal airway and 
in patients with maxillary crossbite with high palatal arches than in normal individuals (Laptook, 1981; Peyvandi et al., 2014). However, it is difficult to recognize which of these factors are responsible for hearing loss.

Table 2. Means and standard deviations of pure-tone thresholds, airbone gaps at various speech frequencies Group 2

\begin{tabular}{|c|c|c|c|c|}
\hline \multirow{2}{*}{$\begin{array}{l}\text { Frequency } \\
(\mathrm{Hz})_{-}\end{array}$} & \multicolumn{2}{|c|}{ T0 } & \multicolumn{2}{|c|}{ T2 } \\
\hline & $\begin{array}{c}\text { Mean } \\
(\mathrm{dB})\end{array}$ & Std & $\begin{array}{c}\text { Mean } \\
(\mathrm{dB})\end{array}$ & Std \\
\hline \multicolumn{5}{|l|}{$\begin{array}{l}\text { PTT a }^{\text {a }} 250 \mathrm{~Hz}\end{array}$} \\
\hline Right ear & 20.50 & 6.85 & 18.50 & 9.73 \\
\hline Left ear & 22.50 & 9.79 & 18.50 & 7.84 \\
\hline \multicolumn{5}{|l|}{$500 \mathrm{~Hz}$} \\
\hline Right ear & 16.50 & 6.25 & 17.00 & 7.89 \\
\hline Left ear & 20.50 & 10.91 & 16.50 & 6.26 \\
\hline \multicolumn{5}{|l|}{$1000 \mathrm{~Hz}$} \\
\hline Right ear & 13.00 & 4.21 & 14.00 & 7.75 \\
\hline Left ear & 17.00 & 8.23 & 13.00 & 3.49 \\
\hline \multicolumn{5}{|l|}{$2000 \mathrm{~Hz}$} \\
\hline Right ear & 10.50 & 4.38 & 14.50 & 8.96 \\
\hline Left ear & 14.50 & 4.97 & 11.50 & 4.12 \\
\hline \multicolumn{5}{|l|}{$\begin{array}{l}\text { ABG }{ }^{b} \\
500 ~ H z\end{array}$} \\
\hline Right ear & 12.00 & 7.15 & 10.00 & 5.27 \\
\hline Left ear & 16.50 & 13.34 & 10.50 & 7.62 \\
\hline \multicolumn{5}{|l|}{$1000 \mathrm{~Hz}$} \\
\hline Right ear & 11.00 & 6.58 & 7.00 & 5.87 \\
\hline Left ear & 14.00 & 10.22 & 7.50 & 7.17 \\
\hline \multicolumn{5}{|l|}{$2000 \mathrm{~Hz}$} \\
\hline Right ear & 5.50 & 3.69 & 7.00 & 7.53 \\
\hline Left ear & 10.00 & 5.27 & 5.00 & 6.67 \\
\hline
\end{tabular}

a: Pure-tone thresholds, ${ }^{\text {b: }}$ Air-bone gap

There have been many studies that investigated the effect of maxillary expansion on conductive hearing loss (Ceylan et al., 1996; Kılıç et al., 2008; Kılıç et al., 2016). Although maxillary expansion is not one of the main treatment alternatives in those patients, past studies emphasized that maxillary expansion had a positive effect on healing of hearing levels of patients with conductive hearing loss. The effect of maxillary expansion on hearing loss may be explained by two factors. First, expansion seems to be associated with an increase in nasal cavity width and volume and a decrease in nasal airway resistance (Hershey et al., 1976; Başçiftçi et al., 2002; Buck et al., 2016). Additionally, maxillary expansion affects more distant structures and stretching of the tensor and veli palatini muscles that open the pharyngeal orifice of the Eustachian tube allowing air to pass through the tube (Ross, 1971; Fingeroth, 1990). If air passes through the tube, pressures are balanced and the ossicular chain can vibrate freely and function normally (Bluestone, 2004). However, expansion opens the palate as if on a hinge at the base of the nose. The amount of lateral movement decreases from the teeth toward the nose, so ends of the muscles were less effected than dentition from amount of expansion.

OME occurs commonly during childhood, with as many as $90 \%$ of children having at least one episode of OME by the age of 10 (Berkman et al., 2013). Some past studies used rapid expansion to examine the effect of maxillary expansion in early mixed dentition patients (Villano et al., 2006; Cozza et al., 2007). In the present study every patient was above 10 years old and so we chose rapid expansion. Slow expansion may be used if it is applied in small children with OME.

Although similar studies emphasized the positive effect of maxillary expansion in OME patients, most of these studies did not have a control group without treatment to compare the healing or spontaneous resolution of OME (Ceylan et al., 1996; Taşpınar et al., 2003; Kılıç et al., 2008). Only Kiliç et al. included ventilation tube and control groups, but the control group consisted of healthy subjects with no orthodontic or rhinologic problems or systemic disorders (Kılıç et al., 2016). In our study we included a control group with OME without maxillary construction. In this way, we had the opportunity to compare the amount of spontaneous resolution and the effect of maxillary expansion. In the control group of this study we managed the subjects with OME who were not at risk with watchful waiting for three months from the date of diagnosis.

Magnitude of the hearing loss could be defined with puretone thresholds. The decrease of the mean pure-tone thresholds values shows the improvement of the hearing loss. There are different results in the literature about hearing improvements after maxillary expansion. Some studies reported improvement of nearly 15-20 decibels after maxillary expansion (Villano et al., 2006; Kılıç et al., 2016), although this healing is 2-6 decibels according to others (Kılıç et al., 2008). The hearing threshold results of the expansion group in our study presented a significant improvement of 5.42 decibels just after expansion. Then a small degree of relapse occurred during the retention period. In the control group thresholds were also decreased 1.44 decibels but this healing was not significant. However, there was no significant difference between the hearing improvements of the groups when T2-T0 thresholds measurements were compared. 
Table 3. Intra group comparison of the pure-tone thresholds at different times

\begin{tabular}{|c|c|c|c|c|c|c|}
\hline Group & $\begin{array}{l}\text { Pure-tone } \\
\text { thresholds }\end{array}$ & $\mathbf{N}$ & Mean $\pm \operatorname{Std}(d B)$ & $\mathbf{F}$ & $\mathbf{p}$ & Difference \\
\hline \multirow{5}{*}{ Group 1} & T0 & 12 & $21.88 \pm 8.66^{\mathrm{a}}$ & \multirow{5}{*}{4.782} & \multirow{5}{*}{$0.007^{\mathrm{d}}$} & \multirow{5}{*}{$\begin{array}{ll}\text { T0-T1 } & \text { p: } 0.025 \\
\text { T0-T2 } & \text { p:0.982 } \\
\text { T0-T3 } & \text { p: } 0.132 \\
\text { T1-T2 } & \text { p:0.466 } \\
\text { T1-T3 } & \text { p: } 1.000 \\
\text { T2-T3 } & \text { p: } 1.000\end{array}$} \\
\hline & $\mathrm{T} 1$ & 12 & $16.46 \pm 7.29^{b}$ & & & \\
\hline & & & & & & \\
\hline & T2 & 12 & $19.17 \pm 11.61^{\mathrm{a}, \mathrm{b}}$ & & & \\
\hline & $\mathrm{T} 3$ & 12 & $17.76 \pm 9.81^{\mathrm{a}, \mathrm{b}}$ & & & \\
\hline Group & $\begin{array}{l}\text { Pure-tone } \\
\text { thresholds }\end{array}$ & $\mathbf{N}$ & Mean $\pm \operatorname{Std}(\mathbf{d B})$ & $\mathbf{F}$ & & p \\
\hline \multirow{2}{*}{ Group 2} & T0 & 10 & $16.88 \pm 5.49$ & \multirow{2}{*}{0.560} & & \multirow{2}{*}{0.589} \\
\hline & $\mathrm{T} 2$ & 10 & $15.44 \pm 6.13$ & & & \\
\hline
\end{tabular}

${ }^{c}: p<0.05 \quad{ }^{d}: p<0.01 \quad{ }^{a-b}$ describes the significance between T0-T1)

Table 4. Intra group comparison of the air bone gaps at different times

\begin{tabular}{|c|c|c|c|c|c|c|}
\hline Group & $\mathbf{A B G}^{\mathrm{d}}$ & $\mathbf{N}$ & Mean \pm Std & $\mathbf{F}$ & $\mathbf{p}$ & Difference \\
\hline \multirow{4}{*}{ Group 1} & T0 & 12 & $11.46 \pm 4.70^{\mathrm{a}}$ & \multirow{4}{*}{3.189} & \multirow{4}{*}{$0.036^{\circ}$} & \multirow{4}{*}{$\begin{array}{ll}\text { T0-T1 } & \mathrm{p}: 0.021^{\mathrm{c}} \\
\text { T0-T2 } & \mathrm{p}: 0.473 \\
\text { T0-T3 } & \mathrm{p}: 0.366 \\
\text { T1-T2 } & \mathrm{p}: 1.000 \\
\text { T1-T3 } & \mathrm{p}: 1.000 \\
\text { T2-T3 } & \mathrm{p}: 1,000\end{array}$} \\
\hline & $\mathrm{T} 1$ & 12 & $7.71 \pm 5.22^{\mathrm{b}}$ & & & \\
\hline & $\mathrm{T} 2$ & 12 & $8.61 \pm 7.64^{\mathrm{a}, \mathrm{b}}$ & & & \\
\hline & $\mathrm{T} 3$ & 12 & $8.19 \pm 7.33^{\mathrm{a}, \mathrm{b}}$ & & & \\
\hline Group & $\mathrm{ABG}^{\mathrm{d}}$ & $\mathbf{N}$ & Mean \pm Std & $\mathbf{F}$ & & $\mathbf{p}$ \\
\hline \multirow{2}{*}{ Group 2} & T0 & 10 & $11.50 \pm 6.64$ & \multirow{2}{*}{2.369} & & \multirow{2}{*}{$0.042^{\mathrm{c}}$} \\
\hline & $\mathrm{T} 2$ & 10 & $7.83 \pm 5.43$ & & & \\
\hline
\end{tabular}

c: $p<0.05{ }^{\mathrm{d}}$ : Air-bone gap, $\left({ }^{\mathrm{a}-\mathrm{b}}\right.$ describes the significance between T0-T1)

Table 5. Values of pressure, tympanic compliance and volumetric measurement of the groups and comparison of the values in different times

\begin{tabular}{|c|c|c|c|c|}
\hline & & $\begin{array}{c}\text { Pressure } \\
\text { Mean } \pm \text { Std }\end{array}$ & $\begin{array}{c}\text { Compliance } \\
\text { Mean } \pm \text { Std }\end{array}$ & $\begin{array}{c}\text { Volume } \\
\text { Median (Min-Max) }\end{array}$ \\
\hline \multirow{5}{*}{ 1.Group } & T0 & $-135.88 \pm 103.89^{\mathrm{a}}$ & $0.62 \pm 0.42^{\mathrm{a}}$ & $0.73(0.50-1.10)^{\mathrm{a}, \mathrm{b}}$ \\
\hline & $\mathrm{T} 1$ & $-95.42 \pm 115.14^{\mathrm{a}}$ & $0.63 \pm 0.41^{\mathrm{a}}$ & $0.80(0.55-5.00)^{\mathrm{a}}$ \\
\hline & $\mathrm{T} 2$ & $-117.75 \pm 119.93^{\mathrm{a}}$ & $0.62 \pm 0.46^{\mathrm{a}}$ & $0.64(0.40-1.31)^{\mathrm{b}}$ \\
\hline & $\mathrm{T} 3$ & $-114.33 \pm 119.81^{\mathrm{a}}$ & $0.68 \pm 0.47^{\mathrm{a}}$ & $0.65(0.45-1.00)^{\mathrm{a}, \mathrm{b}}$ \\
\hline & & Mean \pm Std & Mean \pm Std & Median (Min-Max) \\
\hline \multirow{2}{*}{ 2.Group } & T0 & $-136.30 \pm 131.19^{a}$ & $0.89 \pm 1.09^{\mathrm{a}}$ & $0.70(0.50-1.60)^{\mathrm{a}}$ \\
\hline & $\mathrm{T} 2$ & $-136.60 \pm 132.90^{\mathrm{a}}$ & $1.21 \pm 1.79^{\mathrm{a}}$ & $0.93(0.50-6.00)^{\mathrm{a}}$ \\
\hline
\end{tabular}

Table 6. Hearing level and air-bone gaps change from first record period to 3 months retention period (T0-T2) and comparison of the groups

\begin{tabular}{llccccc} 
& \multicolumn{4}{c}{ Pure-tone thresholds } & \multicolumn{2}{c}{ Air bone gap } \\
Group & N & Mean \pm Std (dB) & $\mathbf{p}$ & Mean \pm Std (dB) & p \\
\hline Group 1 & 12 & $2.71 \pm 6.29$ & & $2.85 \pm 5.09$ & 0.706 \\
Group 2 & 10 & $1.44 \pm 8.12$ & 0.683 & $3.67 \pm 4.89$ &
\end{tabular}

We used a 10-decibel ABG to diagnose conductive hearing loss. But the ABG was decreasing at $2000 \mathrm{~Hz}$ for almost all of the patient's tests. This typical closure was because of the elevation of air conduction at $2000 \mathrm{~Hz}$ as reported in a current review (Haggard et al., 2012). Unfortunately, the air-bone gap value at $2000 \mathrm{~Hz}$ was decreasing the average of the air bone gap obtained from three frequencies $(500 \mathrm{~Hz}, 1000 \mathrm{~Hz}$ and $2000 \mathrm{~Hz})$. 
ABGs decreased at a statistically significant level in the expansion group just after the expansion period. The level of decrease was similar to that reported by Taspinar et al. (2003) and Kiliç et al. (2008). The findings of the present study showed that ABGs decreased significantly just after maxillary expansion and then a relapse occurred during the retention period. However, there are no other studies that examined ABGs of a control group in the literature. In the control group, ABGs, which play a significant role in determining OME diagnosis, decreased significantly. There was also no significant difference between the ABGs of the groups when T2-T0 measurements were compared. Both groups' ABGs were under 10 decibels at the end of the study.

Tympanometry allows the evaluation of ET dysfunctions and assesses transmission, volume and pressure in the middle ear. Measurements of middle air pressure, and tympanic compliance help the clinician to determine changes in the stiffness of the tympanic membrane, reductions in middle-ear effusion, and volumetric changes of the ear canal (Taspınar et al., 2003; Gerardo lazo-sáenz. et al., 2005). Ventilation of the tympanic cavity with normal functioning of the tube creates an increase in the volume. In our study volume was increased after expansion but showed a degree of relapse during the retention period. Pressure and tympanic compliance values did not change significantly in either group during the observation period of this study.

\section{References}

1. Brantingham, J.W., Bonnefin, D., Perle, S.M., Cassa, T.K., Globe, G., Pribicevic, M., Hicks, M., Korporaal, C. 2012. Manipulative therapy for lower extremity conditions: update of a literature review. J. Manipulative Physiol. Ther. 35(2):127-166.

2. Basciftci, F., Mutlu, N., Karaman, A., Malkoc, S., Küçükkolbasi, H. 2002. Does the timing and method of rapid maxillary expansion have an effect on the changes in nasal dimensions? Angle. Orthod.72(2):118-123.

3. Berkman, N.D., Wallace, I.F., Steiner, M.J., Harrison, M., Greenblatt, A.M., Lohr, K.N., Kimple, A., Yuen, A. 2013. Otitis media with effusion: comparative effectiveness of treatments. [Internet] Rockville, MD: Agency for Healthcare Research and Quality (US); Report No: 13-EHC091-EF.

4. Bluestone, C.D., 2004. Studies in otitis media: Children's hospital of Pittsburgh-University of Pittsburgh progress report-2004. Laryngoscope. 114 (105):1-26.

5. Buck, L.M., Dalci, O., Darendeliler, M.A., Papageorgiou, S.N., Papadopoulou, A.K. 2017. Volumetric upper airway changes after rapid maxillary expansion: a systematic review and meta-analysis. Eur. J. Orthod. 39 (5): 463-473.

6. Ceylan, I., Oktay, H., Demirci, M. 1996. The effect of rapid maxillary expansion on conductive hearing loss. Angle. Orthod. 66 (4): 301-308.

7. Cozza, P., Di Girolamo, S., Ballanti, F., Panfilio, F. 2007. Orthodontist-otorhinolaryngologist: an interdisciplinary approach to solve otitis media. Eur. J. Paediatr. Dent. 8 (2): 83-88.

8. Fingeroth, A. 1990. Orthodontic-orthopedics as related to respiration and conductive hearing loss. J. Clin. Pediatr. Dent. 15 (2):83-89.

9. Flynn, T., Möller, C., Jönsson, R., Lohmander, A. 2009. The high
The major limitation with the study is the small sample size. We think the studies with larger population are unlikely to be forthcoming because of methodologic and ethical difficulties inherent in studying children with hearing loss and at risk for further delays.

When measuring hearing, there is always an error of measurement of at least $5-10 \mathrm{~dB}$ that needs to be taken into consideration as the child needs to concentrate and cooperate. We tried to minimize this problem by repeating the tests a few times to be sure and by the same audiologist. Of course, the serious hearing loss amounts could not be the subjects of this current study.

In this study $\mathrm{ABGs}$ and hearing thresholds were decreased in the maxillary expansion group at $\mathrm{T} 1$ and at the end of retention and six months after the expansion period and a small relapse occurred. Hearing thresholds did not show a significant difference in the control group after three months of watchful waiting, but ABGs were decreased significantly. There was no significant difference in the rate of healing of pure-tone thresholds and ABGs of the groups when T2-T0 values were compared.

In conclusion, RME, when applied within orthodontic indication has positive effects in OME patients, but should not be regarded as a major contributor to the treatment of OME.

prevalence of otitis media with effusion in children with cleft lip and palate as compared to children without clefts. Int. J. Pediatr. Otorhinolaryngol. 73(10):1441-1446.

10. Gan, R., Rowe, A., Benton, C., Daniel, M. 2016. Management of hearing loss in children. Paediatrics and Child Health. 26 (1):1520.

11. Gerardo lazo-sáenz, J, Galván-Aguilera, A.A. Martínez-Ordaz, V.A., Velasco-Rodríguez, V.M., Nieves-Rentería, A., RincónCastañEda, C. 2005. Eustachian tube dysfunction in allergic rhinitis. Otolaryngol. Head. Neck. Surg. 132 (4):626-629.

12. MRC Multicentre Otitis Media Study Group. 2012. Adjuvant adenoidectomy in persistent bilateral otitis media with effusion: hearing and revision surgery outcomes through 2 years in the TARGET randomised trial. Clin. Otolaryngol.37(2):107-116.

13. Hershey, H.G., Stewart, B.L., Warren, D.W. 1976. Changes in nasal airway resistance associated with rapid maxillary expansion. Am. J. Orthod. 69 (3): 274-284.

14. Kilic N, Kiki A, Oktay H, Selimoglu E. 2008. Effects of rapid maxillary expansion on conductive hearing loss. Angle. Orthod. 78 (3): 409-414.

15. Kiliç, N., Yörük, Ö., Kiliç, S.C., Çatal, G., Kurt, S. 2016. Rapid maxillary expansion versus middle ear tube placement: Comparison of hearing improvements in children with resistance otitis media with effusion. Angle. Orthod. 86 (5):761-767.

16. Kuo, C.L., Tsao, Y.H., Cheng, H.M., Lien, C.F., Hsu, C.H., Huang, C.Y., Shiao, A.S. 2014. Grommets for otitis media with effusion in children with cleft palate: A systematic review. Pediatrics. 134(5):983-994.

17. Laptook, T. 1981. Conductive hearing loss and rapid maxillary expansion: report of a case. Am. J. Orthod. 80(3):325-331. 
18. McNamara, J.A., Brudon, W.L.1993. Orthodontic and orthopedic treatment in the mixed dentition. Needham Press.

19. Peyvandi, A., Jamilian, A., Moradi, E. 2014. Relationship between conductive hearing loss and maxillary constriction. J. Laryngol. Otol.128 (09):765-767.

20. Rosenfeld, R.M., Culpepper, L., Doyle, K.J., Grundfast, K.M., Hoberman, A., Kenna, M.A., Lieberthal, A.S., Mahoney, M., Wahl, R.A., Woods, C.R. Jr, Yawn, B. 2004. American Academy of Pediatrics Subcommittee on Otitis Media with Effusion; American Academy of Family Physicians; American Academy of Otolaryngology--Head and Neck Surgery. Clinical practice guideline: Otitis media with effusion. Otolaryngol. Head. Neck. Surg. 130 (5): 95-118.

21. Rosenfeld, R.M., Schwartz, S.R., Pynnonen, M.A., Tunkel, D.E., Hussey, H.M., Fichera, J.S., Grimes, A.M., Hackell, J.M., Harrison, M.F., Haskell, H, Haynes, D.S., Kim, T.W., Lafreniere, D.C, LeBlanc, K., Mackey, W.L., Netterville, J.L., Pipan, M.E., Raol, N.P, Schellhase, K.G. 2013. Clinical practice guideline: Tympanostomy tubes in children. Otolaryngol. Head. Neck. Surg. 149(1): 1-35.

22. Rosenfeld, R.M., Shin, J.J., Schwartz, S.R., Coggins, R., Gagnon, L., Hackell, J.M., Hoelting, D., Hunter, L.L., Kummer, A.W., Payne, S.C., Poe, D.S., Veling, M., Vila, P.M., Walsh, S.A., Corrigan, M.D. 2016. Clinical Practice Guideline Otitis Media with Effusion Executive Summary (Update). Otolaryngol. Head. Neck. Sur. 154 (2): 201-214.
23. Ross, M.A.1971. Functional anatomy of the tensor palati: Its relevance in cleft palate surgery. Arch. Otolaryngol. 93 (1):1-8.

24. Taspinar, F., Üçüncü, H., Bishara, S. 2003. Rapid maxillary expansion and conductive hearing loss. Angle Orthod.73 (6): 669673.

25. Timms, D.1997. Effect of rapid maxillary expansion on hearing loss. Angle. Orthod. 67 (4): 244-246.

26. Venekamp, R.P., Burton M.J., van Dongen T.M., van der Heijden G.J., van Zon A., Schilder A.G. 2016. Antibiotics for otitis media with effusion in children. Cochrane. Database. Syst Rev. 12 (6): CD009163.

27. Villano, A., Grampi, B., Fiorentini, R., Gandini, P. 2006. Correlations between rapid maxillary expansion (RME) and the auditory apparatus. Angle. Orthod. 76 (5): 752-758.

28. Zhang, Q-f, Guo, J., Li, G-f, Zou, S., Zhao, Z. 2010. A potential therapeutic method for conductive hearing loss in growing children-orthodontic expansion treatment. Med. hypotheses. 74 (1): 99-101. 